\title{
Mineração
}

\section{Flotação do carvão contido em um rejeito carbonoso}

\author{
(Froth flotation of coal tailings)
}

\section{Resumo}

Os processos envolvidos no beneficiamento do carvão produzem efeitos nocivos para o meio ambiente, principalmente pela quantidade e natureza dos rejeitos que são gerados. Esses rejeitos, comumente denominados "piritosos", mesmo não apresentando altos conteúdos de pirita, constituem-se em um material ácido que causa efeitos nocivos ao meio ambiente, principalmente aos corpos de água. Esses rejeitos, geralmente, são depositados em barragens de rejeitos.

O rejeito carbonoso estudado nessa pesquisa provem de um processo de beneficiamento que envolve ciclones de meio denso e espirais. A caracterização revelou que ele possui teor de cinzas de $56 \%$ e poder calorífico de $5.800 \mathrm{BTU} / \mathrm{lb}$, sendo que o conteúdo de enxofre é 1,2\%. Em termos de granulometria, o material é considerado ultrafino já que $63 \%$ é menor que $0,014 \mathrm{~mm}$.

O conteúdo de matéria carbonosa deste rejeito é facilmente recuperado por flotação, como se demonstra nesse trabalho. É possível recuperar $74 \%$ da matéria carbonosa e obter um produto com 7,3\% de cinzas e poder calorífico de 14.225 BTU/lb em base seca.

Palavras-chave: Carvão, flotação, rejeitos.

\section{Astrid Sofia Ruiz}

Mestranda em Engenharia Mineral Escola Politécnica da Universidade de

São Paulo

E-mail:asofia.ruiz@usp.br

\section{Arthur Pinto Chaves}

Professor Titular de Tratamento de Minérios, Departamento de Engenharia de Minas e Petróleo, Escola Politécnica da Universidade de São Paulo E-mail: apchaves@usp.br

\section{Abstract}

The processes involved in coal preparation produce harmful effects for the environment, mainly by the quantity and nature of wastes that are generated. These tailings generally called "pyritic", even though not presenting a high pyrite content, are an acid material harmful to the environment. These tailings are usually disposed of in tailings dams.

The tailings, studied in this work come from a process involving densemedium cyclones and spirals. They have an ash content of 56\% and a calorific value of 5,800 BTU/Lb, the sulfur content is $1.2 \%$. In terms of size, the material is considered as ultrafine, as $63 \%$ of it is less than 0,014 $\mathrm{mm}$.

The coal matter content of these tailings is easily recovered by froth flotation, as evidenced in this work. It's possible to recover $74 \%$ of the coal matter and to obtain a product with $7.3 \%$ ash and calorific value of 14,225 BTU / lb in dry basis.

Keywords: Coal, froth flotation, tailings. 


\section{Introdução}

O objetivo desse trabalho é o demonstrar a viabilidade da recuperação do carvão contido num rejeito carbonoso. Tal recuperação propiciaria a obtenção de um concentrado de carvão que atinja as especificações do mercado e que possa ser aproveitado como combustível na geração de energia elétrica. Esse aproveitamento se constituiria em um fator de diminuição do impacto ambiental da barragem de rejeitos, possibilitando, também, a aplicação do princípio da conservação dos recursos minerais.

A flotação de carvão surgiu como solução técnica para a limpeza das águas negras oriundas das usinas de lavagem. Flotou-se o carvão para limpar a água e verificou-se que esse carvão flotado apresentava excelente qualidade, o que se explica devido à liberação total desse carvão muito fino.

A estrutura química dos carvões é formada por hidrocarbonetos de cadeia longa e estruturas cíclicas, a qual determina a propriedade de hidrofobicidade natural. Substâncias hidrofóbicas, em teoria, não precisam da adição de coletor, mas de reforçadores da hidrofobicidade, os quais se espalham sobre a superfície da partícula de carvão e aumentam o grau de hidrofobicidade, favorecendo a flotação. Meneses et al. (2006) afirmam que esses "coletores" se aderem à superfície do carvão por um mecanismo denominado adesão ou efeito de segregação (squeezing out effect). Esses óleos não têm afinidade pela fase aquosa, então são segregados dela indo se depositar na superfície do carvão e, assim, reforçar a coleta. Chaves (1983) explica que o modelo mais aceito de adsorção do óleo na superfície do carvão é por adsorção física, a qual é devida às forças de Van der Waals e esse efeito de segregação consiste na expulsão das moléculas graxas do seio da solução para a interface de outra fase com a qual tenham mais afinidade. Nesse caso, serão as substâncias orgânicas dos macerais do carvão.

Os "coletores" tradicionalmente usados na flotação direta do carvão são o óleo diesel e querosene, mas, em ca- sos especiais, são usados: óleo combustível (em associação com MIBC), alcatrões (em associação com querosene), creosoto e aminas de cadeia longa para carvões oxidados.

A pirita apresenta alta atividade superficial e tende a flotar junto com o carvão, portanto é comum deprimi-la usando reagentes como os cloretos férricos, de alumínio e crômio, cloretos de sódio ou potássio e cal.

Os espumantes mais usados na flotação de carvão são o óleo de pinho e o metil-isobutil-carbinol (MIBC). Atribuem-se propriedades coletoras ao óleo de pinho. Uma possível explicação para esse fato é que os espumantes são moléculas polares e não-polares e pode haver uma atração elétrica entre a porção polar da molécula e os sítios portadores de minerais na superfície do carvão. Chaves (1983) atribui esse comportamento ao fato de a espuma de óleo de pinho ser consistente, já que, dessa maneira, a espuma é capaz de arrastar, mecanicamente, partículas carbonosas. O espumante MIBC gera espumas mais ralas e bolhas maiores, o que permite melhor drenagem da ganga, portanto a recuperação mássica é menor, mas esse espumante é mais seletivo, e isto é atribuído, tanto à ausência de propriedades coletoras, como à qualidade da espuma.

A flotação de carvões trabalha com granulometrias muito mais grossas que as dos outros minérios isto acontece devido à baixa densidade do carvão. A norma ASTM (D5114) considera que carvões de baixo rank apresentam melhor comportamento na flotação com tamanhos máximos de $420 \mathrm{~mm}$ ou 35\# série Tyler. A oxidação do carvão começa com a adsorção física do oxigênio na superfície, por isso é importante trabalhar com partículas tão grossas quanto possível.

Mitchell et al. (1996) demonstraram através de medidas do ângulo de contato, que, para carvões de baixo rank, a baixa flotabilidade é atribuída ao efeito da oxidação. Chaves (1983) e Polat et al. (2003) apud Wen (1977) atribuem essas variações de flotabilidade a efeitos eletrocinéticos, já que, conforme se diminui o rank, maior a quantidade de grupos que contêm oxigênio, como carboxilas e hidroxilas, os quais mudam o valor do potencial zeta da partícula.

Na flotação de minérios metálicos, trabalha-se com diluição de polpa em torno de $20-25 \%$ de sólidos. Como o carvão é mais leve, para se obter o mesmo volume em suspensão se deve ter uma polpa com uma porcentagem de sólidos mais alta. A norma ASTM (D5114) indica que os valores devem estar entre 6-10\%. No caso da flotação direta de carvão, o pH é uma variável importante apenas pelas interações da matéria mineral e não pela natureza da matéria carbonosa, portanto o pH deverá ser controlado nos casos de depressão de pirita e em casos onde sejam importantes as interações da matéria mineral e os reagentes. Zimmerman (1979) estabeleceu que, no caso de carvões estadunidenses, as mais altas recuperações são para $\mathrm{pH}$ entre 6 e 7,5.

\section{Materiais e métodos}

A amostra coletada na barragem foi estocada em sacos plásticos, selada para isolá-la do ar e enviada ao Laboratório de Tratamento de Minérios e Resíduos Industriais (LTM), da Escola Politécnica da USP. Foi caracterizada por análise granulométrica e determinação da mineralogia das cinzas por difração de raios X.

A preparação das amostras para flotação iniciou-se com a eliminação da fração acima de 35\#. Posteriormente a polpa foi ajustada para uma porcentagem de sólidos entre 6 e $8 \%$ em massa.

Realizaram-se ensaios em bancada em uma máquina de flotação Denver, a $1.100 \mathrm{rpm}$ e usando célula com capacidade de 2,8 L, sempre com $\mathrm{pH}$ de 7,3. Os ensaios de flotação foram planejados começando com uma etapa exploratória, sendo que o principal objetivo foi identificar os reagentes e as dosagens ótimas. A segunda etapa consistiu em ensaios sistemáticos, nos quais se variaram as dosagens dos reagentes, em torno do ponto ótimo encontrado nos ensaios exploratórios, $\pm 500 \mathrm{~g} / \mathrm{t}$. 
Astrid Sofia Ruiz et al.

Depois, realizou-se o denominado ensaio "locked cycle" ou de circuito fechado, que permitiu simular uma operação contínua de flotações sucessivas, com etapas rougher, scavenger e cleaner, onde se recircularam os fluxos intermediários e introduziu-se alimentação nova em cada corrida.

Em todos os ensaios, as amostras, tanto de cabeça, como de produtos e rejeitos, foram submetidas à análise imediata completa e algumas delas com determinação de enxofre. Fizeram-se esses ensaios seguindo a metodologia contida na norma ASTM(D3172). A Figura 1 esquematiza o plano de pesquisa.

\section{Resultados}

A análise granulométrica foi realizada por peneiramento via úmida até o tamanho $74 \mu \mathrm{m}$ e com ciclosizer para as frações mais finas. A Tabela 1 mostra os resultados dessa análise.

A densidade real, obtida com picnômetro, para o material de cabeça, é 2,0. Foi feita análise imediata para se determinarem os parâmetros de qualidade do rejeito estudado, sendo que os resultados estão contidos na Tabela 2 .

A difração de raios $\mathrm{X}$ das cinzas revelou a assembléia mineral, mostrada na Tabela 3.

\subsection{Ensaios exploratórios}

O objetivo foi encontrar os reagentes mais apropriados e a dosagem em que a recuperação de massa fosse maior e o teor de cinzas suficientemente baixo. A primeira fase foi realizada partindo de uma dosagem de $2.000 \mathrm{~g} / \mathrm{t}$, no caso do querosene, e $1.000 \mathrm{~g} / \mathrm{t}$, para o óleo diesel (com incrementos de $1.000 \mathrm{~g} / \mathrm{t}$ ). Essas
Tabela 1 - Análise granulométrica.

\begin{tabular}{c|c|c}
\hline Abertura em mm & \% Massa & \% Retido acumulado \\
\hline 6,35 & 0,39 & 0,39 \\
\hline 3,35 & 0,34 & 0,73 \\
\hline 2,36 & 0,17 & 0,90 \\
\hline 1,00 & 0,60 & 1,51 \\
\hline 0,50 & 1,17 & 2,68 \\
\hline 0,25 & 1,85 & 4,53 \\
\hline 0,105 & 7,10 & 11,63 \\
\hline 0,074 & 4,69 & 16,33 \\
\hline 0,056 & 0,66 & 16,98 \\
\hline 0,042 & 0,79 & 17,77 \\
\hline 0,029 & 2,24 & 20,02 \\
\hline 0,019 & 7,68 & 27,69 \\
\hline 0,014 & 9,35 & 37,04 \\
\hline$-0,014$ & 62,96 & 100,00 \\
\hline & & \\
\hline & & \\
\hline
\end{tabular}

Tabela 2 - Parâmetros de qualidade.

\begin{tabular}{c|c}
\hline Parâmetro & Valor \\
\hline Umidade residual & $2,61 \%$ \\
\hline Conteúdo de cinza & $51,86 \%$ \\
\hline Conteúdo de voláteis & $27,40 \%$ \\
\hline Enxofre & $1,20 \%$ \\
\hline Poder calorífico & 5,743 BTU/Lb
\end{tabular}

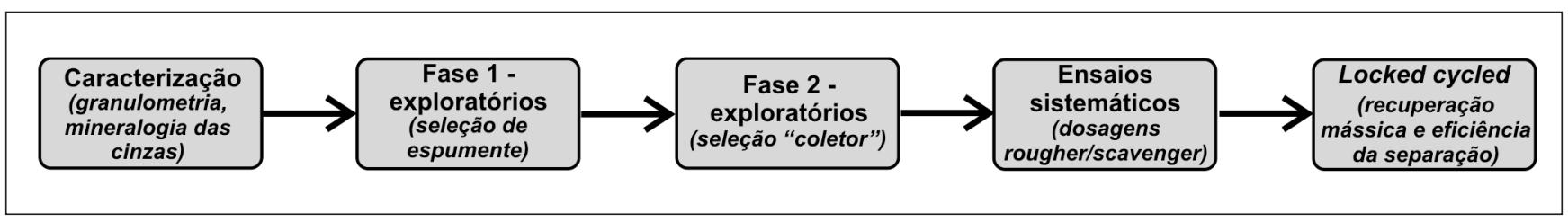

Figura 1 - Plano de pesquisa. 
Flotação do carvão contido em um rejeito carbonoso

dosagens aparentemente altas se devem à extrema finura do material, com a conseqüente área de superfície muito elevada. Realizaram-se flotações sucessivas até obter toda a matéria carbonosa. A Tabela 4 mostra os resultados desses ensaios.

Pode-se verificar que a recuperação de matéria carbonosa do espumante MIBC é menor que a recuperação obtida com óleo de pinho. Decidiu-se, então, continuar a pesquisa com esse último.
Tabela 3 - Assembléia mineral das cinzas.

\begin{tabular}{c|c}
\hline Mineral identificado & Formula química \\
\hline Quartzo & $\mathrm{SiO}_{2}$ \\
\hline Muscovita & $\left(\mathrm{K}_{0.82} \mathrm{Na}_{0.12}\right)\left(\mathrm{Fe}_{0.03} \mathrm{Al}_{1.97}\right)\left(\mathrm{AlSiO}_{3}\right) \mathrm{O}_{10}(\mathrm{OH})_{2}$ \\
\hline Pirita & $\mathrm{FeS2}$ \\
\hline Clinocloro & $(\mathrm{Mg}, \mathrm{Fe})_{6}(\mathrm{Si}, \mathrm{Al})_{4} \mathrm{O}_{10}(\mathrm{OH})_{8}$ \\
\hline Caulinita & $\mathrm{Al}_{2} \mathrm{Si}_{2} \mathrm{O}_{5}(\mathrm{OH})_{4}$ \\
\hline
\end{tabular}

Tabela 4 - Ensaios exploratórios primeira fase.

\begin{tabular}{|c|c|c|c|c|c|c|c|c|c|c|c|c|}
\hline \multirow{2}{*}{ Ensaio } & \multirow{2}{*}{ Produto } & \multicolumn{2}{|c|}{$\begin{array}{l}\text { Dosagem } \\
\text { "coletor" }\end{array}$} & \multicolumn{2}{|c|}{$\begin{array}{c}\text { Dosagem } \\
\text { espumante }\end{array}$} & \multicolumn{2}{|c|}{$\%$ Massa } & \multicolumn{2}{|c|}{$\begin{array}{c}\text { Teor de } \\
\text { cinzas (\%) }\end{array}$} & \multicolumn{3}{|c|}{ Matéria carbonosa } \\
\hline & & $g / t$ & Acum. & $g / t$ & Acum. & $\%$ & Acum & Teor & Acum. & Teor & Recup. & $\begin{array}{l}\text { Recup. } \\
\text { Acum. }\end{array}$ \\
\hline \multirow{7}{*}{ 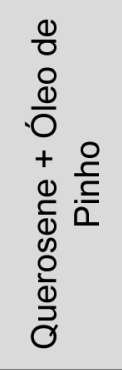 } & 1 & 2.000 & 2.000 & 233 & 233 & 3,9 & 3,9 & 9,6 & 9,6 & 90,4 & 8,1 & 8,1 \\
\hline & 2 & 1.000 & 3.000 & 116 & 349 & 20,2 & 24,1 & 17,6 & 16,3 & 82,4 & 38,1 & 46,2 \\
\hline & 3 & 1.000 & 4.000 & 116 & 466 & 20,3 & 44,4 & 16,1 & 16,2 & 83,9 & 38,9 & 85,0 \\
\hline & 4 & 1.000 & 5.000 & 116 & 582 & 6,4 & 50,8 & 42,0 & 19,4 & 58,0 & 8,4 & 93,5 \\
\hline & 5 & 1.000 & 6.000 & 116 & 699 & 9,1 & 59,9 & 82,8 & 29,1 & 17,2 & 3,6 & 97,1 \\
\hline & Deprimido & & & & & 40,1 & 100,0 & 96,8 & 56,2 & & & \\
\hline & Alimentação & & & & & 100,0 & & 56,2 & & 43,8 & & \\
\hline \multirow{6}{*}{ 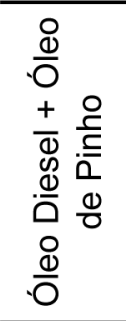 } & 1 & 1.000 & 1.000 & 163 & 163 & 4,1 & 4,1 & 9,8 & 9,8 & 90,2 & 7,7 & 7,7 \\
\hline & 2 & 1.000 & 2.000 & 163 & 325 & 26,0 & 30,0 & 13,6 & 13,1 & 86,4 & 47,1 & 54,7 \\
\hline & 3 & 1.000 & 3.000 & 163 & 488 & 13,8 & 43,8 & 16,3 & 14,1 & 83,7 & 24,3 & 79,0 \\
\hline & 4 & 1.000 & 4.000 & 163 & 650 & 3,7 & 47,5 & 33,2 & 15,6 & 66,8 & 5,1 & 84,1 \\
\hline & Deprimido & & & & & 52,5 & 100,0 & 85,6 & 52,3 & 14,4 & & \\
\hline & Alimentação & & & & & 100,0 & & 52,3 & & 47,7 & & \\
\hline \multirow{7}{*}{ 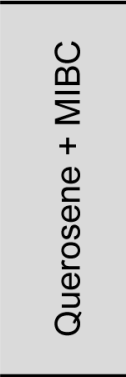 } & 1 & 2.000 & 2.000 & 300 & 300 & 2,0 & 2,0 & 7,5 & 7,5 & 92,5 & 4,5 & 4,5 \\
\hline & 2 & 1.000 & 3.000 & 153 & 453 & 15,3 & 17,3 & 9,0 & 8,8 & 91,0 & 33,9 & 38,5 \\
\hline & 3 & 1.000 & 4.000 & 153 & 606 & 13,4 & 30,7 & 11,8 & 10,1 & 88,2 & 28,8 & 67,3 \\
\hline & 4 & 1.000 & 5.000 & 153 & 759 & 6,9 & 37,6 & 15,2 & 11,1 & 84,8 & 14,3 & 81,5 \\
\hline & 5 & 1.000 & 6.000 & 153 & 912 & 5,9 & 43,5 & 25,3 & 13,0 & 74,7 & 10,7 & 92,3 \\
\hline & Deprimido & & & & & 56,5 & 100,0 & 94,4 & 59,0 & 5,6 & & \\
\hline & Alimentação & & & & & 100,0 & & 59,0 & & 41,0 & & \\
\hline \multirow{5}{*}{ 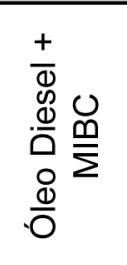 } & 1 & 1.000 & 1.000 & 153 & 153 & 2,9 & 2,9 & 11,9 & 11,9 & 88,1 & 5,6 & 5,6 \\
\hline & 2 & 1.000 & 2.000 & 153 & 306 & 20,1 & 23,0 & 13,7 & 13,5 & 86,3 & 37,9 & 43,5 \\
\hline & 3 & 1.000 & 3.000 & 306 & 612 & 15,6 & 38,6 & 15,5 & 14,3 & 84,5 & 28,8 & 72,3 \\
\hline & Deprimido & & & & & 61,4 & 100,0 & 79,4 & 54,2 & 20,7 & & \\
\hline & Alimentação & & & & & 100,0 & & 54,2 & & 45,8 & & \\
\hline
\end{tabular}


Astrid Sofia Ruiz et al.

Segundo os resultados obtidos, nesses ensaios, para o caso do querosene e óleo de pinho inicialmente poderse-ia pensar que uma boa dosagem para uma etapa rougher seria $3.000 \mathrm{~g} / \mathrm{t}$ de "coletor" e $360 \mathrm{~g} / \mathrm{t}$ de espumante, isto seria complementado com uma etapa scavenger, onde se aumentaria a dosagem em mais $1.000 \mathrm{~g} / \mathrm{t}$ de "coletor" e $120 \mathrm{~g} / \mathrm{t}$ de espumante. No caso do óleo diesel e óleo de pinho, o ponto ótimo para uma etapa rougher é $3000 \mathrm{~g} / \mathrm{t}$ do "coletor" e $490 \mathrm{~g} / \mathrm{t}$ de espumante, depois disto uma etapa scavenger adicionando mais $1500 \mathrm{~g} / \mathrm{t}$ do "coletor" e $160 \mathrm{~g} / \mathrm{t}$ de espumante, na etapa cleaner não haveria adição de reagentes. Realizaram-se, então, ensaios com etapas rougher, scavenger e cleaner com os dois "coletores" e óleo de pinho, isto com o fim de selecionar o "coletor" que melhor recuperação de matéria carbonosa apresente no flotado cleaner. A Tabela 5 apresenta os resultados desses ensaios.

Esse resultado mostra que a maior recuperação de matéria carbonosa acontece em uma flotação com querosene e óleo de pinho. Assim, nesse caso, recupera-se $30,7 \%$. Conclui-se, desses ensaios exploratórios, que, tanto o óleo diesel, como o querosene, têm um bom desempenho como agentes reforçadores da hidrofobicidade. Escolhe-se o querosene para os ensaios apresentados a seguir devido à alta recuperação de matéria carbonosa reportada no flotado.

\subsection{Ensaios sistemáticos}

Realizaram-se os ensaios sistemáticos variando as dosagens do "coletor" nas etapas rougher e scavenger do processo, partindo da dosagem encontrada nos ensaios exploratórios e usando querosene e óleo de pinho. O objetivo é encontrar as dosagens ótimas rougher/scavenger de "coletor" (Tabela 6). Fizeram-se esses ensaios variando $\mathrm{em} \pm 500 \mathrm{~g} / \mathrm{t}$ as dosagens nas etapas rougher e scavenger, sempre tendo como dosagem máxima do ensaio $4.000 \mathrm{~g} / \mathrm{t}$. Não foi feita nenhuma adição de reagente na etapa cleaner.

A melhor recuperação mássica no fluxo do flotado cleaner, se obteve com o querosene nas dosagens de $2.500 \mathrm{~g} / \mathrm{t}$ na etapa rougher e de 1.500 na etapa scavenger. Da mesma maneira, a maior recuperação de matéria carbonosa aconteceu nesse mesmo ensaio, chegandose a $30,7 \%$, e a rejeição de cinzas no deprimido de 94,2\%. Escolheu-se esse ponto para os ensaios apresentados a seguir.

\subsection{Ensaio locked cycle}

$\mathrm{O}$ ensaio de locked cycle consiste em simular, em escala de bancada, uma operação continua, onde os fluxos intermediários (flotado scavenger e deprimido cleaner) são recirculados, e, em cada corrida, se introduz uma nova alimentação. O objetivo desse ensaio é aumentar a recuperação de massa do produto final (flotado cleaner), ao mesmo tempo em que, aumenta a recuperação de matéria carbonosa. A Figura 2 é um esquema de um ensaio locked cycle para $n$ flotações sucessivas. O produto final desse ensaio é o somatório de todos os flotados cleaner (desde o 1 até o $n$ ). Da mesma forma, o rejeito final é a somatórias de todos os deprimidos e a carga circulante

Tabela 5 - Ensaios exploratórios - segunda fase.

\begin{tabular}{|c|c|c|c|c|c|c|c|c|c|}
\hline \multirow{2}{*}{ "Coletor" } & \multirow{2}{*}{ Produto } & \multicolumn{2}{|c|}{$\begin{array}{l}\text { Dosagem } \\
\text { "coletor" }\end{array}$} & \multicolumn{2}{|c|}{$\begin{array}{c}\text { Dosagem } \\
\text { espumante }\end{array}$} & \multirow{2}{*}{$\begin{array}{c}\text { Massa } \\
\text { acum } \\
(\%)\end{array}$} & \multirow{2}{*}{$\begin{array}{c}\text { Teor de } \\
\text { cinzas } \\
(\%)\end{array}$} & \multirow{2}{*}{$\begin{array}{l}\text { Recuperação } \\
\text { de matéria } \\
\text { carbonosa no } \\
\text { flotado } \\
\text { cleaner }(\%)\end{array}$} & \multirow{2}{*}{$\begin{array}{c}\text { Rejeição de } \\
\text { cinzas no } \\
\text { deprimido } \\
(\%)\end{array}$} \\
\hline & & $g / t$ & acum. & g/t & acum. & & & & \\
\hline \multirow{5}{*}{ Querosene } & Dep. cleaner & 3.000 & 3.000 & 360 & 360 & 10,5 & 29,8 & \multirow{5}{*}{30,7} & \multirow{5}{*}{88,9} \\
\hline & Flot. scavenger & 1.000 & 4.000 & 120 & 480 & 9,3 & 17,7 & & \\
\hline & Flot. cleaner & & & & & 15,0 & 9,5 & & \\
\hline & Deprimido & & & & & 65,2 & 76,0 & & \\
\hline & Alimentação & & & & & 101,0 & 55,9 & & \\
\hline \multirow{5}{*}{$\begin{array}{c}\text { Óleo } \\
\text { Diesel }\end{array}$} & Dep. cleaner & 3.000 & 3.000 & 490 & 490 & 3,8 & 40,1 & \multirow{5}{*}{20,4} & \multirow{5}{*}{94,2} \\
\hline & Flot. scavenger & 1.500 & 4.500 & 160 & 650 & 3,6 & 20,0 & & \\
\hline & Flot. cleaner & & & & & 10,3 & 9,1 & & \\
\hline & Deprimido & & & & & 82,3 & 61,9 & & \\
\hline & Alimentação & & & & & 100,0 & 54,1 & & \\
\hline
\end{tabular}


Tabela 6 - Resultados dos ensaios sistemáticos.

\begin{tabular}{|c|c|c|c|c|c|c|c|c|c|}
\hline \multirow{2}{*}{ Ensaio } & \multirow{2}{*}{ Produto } & \multicolumn{2}{|c|}{$\begin{array}{l}\text { Dosagem } \\
\text { "coletor" }\end{array}$} & \multicolumn{2}{|c|}{\begin{tabular}{c|} 
Dosagem \\
espumante
\end{tabular}} & \multirow{2}{*}{$\begin{array}{l}\text { Massa } \\
(\%)\end{array}$} & \multirow{2}{*}{$\begin{array}{c}\text { Teor de } \\
\text { cinzas } \\
(\%)\end{array}$} & \multirow{2}{*}{$\begin{array}{l}\text { Recuperação } \\
\text { de matéria } \\
\text { carbonosa no } \\
\text { flotado } \\
\text { cleaner }(\%)\end{array}$} & \multirow{2}{*}{$\begin{array}{c}\text { Rejeição de } \\
\text { cinzas no } \\
\text { deprimido } \\
(\%)\end{array}$} \\
\hline & & $g / t$ & acum & $g / t$ & acum & & & & \\
\hline \multirow{5}{*}{1} & Dep. cleaner & 2.000 & 2.000 & 240 & 240 & 11,1 & 14,4 & \multirow{5}{*}{17,2} & \multirow{5}{*}{92,8} \\
\hline & Flot. scavenger & 2.000 & 4.000 & 240 & 480 & 16,3 & 12,8 & & \\
\hline & Flot. cleaner & & & & & 7,7 & 7,4 & & \\
\hline & Deprimido & & & & & 64,9 & 83,9 & & \\
\hline & Alimentação & & & & & 100,0 & 58,7 & & \\
\hline \multirow{5}{*}{2} & Dep. cleaner & 2.500 & 2.500 & 300 & 300 & 8,9 & 39,5 & \multirow{5}{*}{39} & \multirow{5}{*}{88,6} \\
\hline & Flot. scavenger & 1.500 & 4.000 & 180 & 480 & 12,3 & 19,5 & & \\
\hline & Flot. cleaner & & & & & 16,8 & 5,0 & & \\
\hline & Deprimido & & & & & 62,0 & 84,4 & & \\
\hline & Alimentação & & & & & 100,0 & 59,1 & & \\
\hline \multirow{5}{*}{3} & Dep. cleaner & 3.000 & 3.000 & 360 & 360 & 7,4 & 19,2 & \multirow{5}{*}{20,4} & \multirow{5}{*}{93,4} \\
\hline & Flot. scavenger & 1.000 & 4.000 & 120 & 480 & 16,6 & 13,1 & & \\
\hline & Flot. cleaner & & & & & 8,5 & 4,5 & & \\
\hline & Deprimido & & & & & 67,5 & 83,2 & & \\
\hline & Alimentação & & & & & 100,0 & 60,1 & & \\
\hline \multirow{5}{*}{4} & Dep. cleaner & 3.500 & 3.500 & 420 & 420 & 5,4 & 38,1 & \multirow{5}{*}{21,2} & \multirow{5}{*}{92,8} \\
\hline & Flot. scavenger & 500 & 4.000 & 60 & 480 & 6,5 & 14,6 & & \\
\hline & Flot. cleaner & & & & & 10,6 & 8,9 & & \\
\hline & Deprimido & & & & & 77,5 & 65,1 & & \\
\hline & Alimentação & & & & & 100,0 & 54,4 & & \\
\hline \multirow{5}{*}{5} & Dep. cleaner & 4.000 & 4.000 & 480 & 480 & 10,2 & 46,8 & \multirow{5}{*}{26,6} & \multirow{5}{*}{89,1} \\
\hline & Flot. scavenger & 0 & 4000 & 0 & 480 & 0,0 & 0,0 & & \\
\hline & Flot. cleaner & & & & & 13,0 & 9,6 & & \\
\hline & Deprimido & & & & & 76,8 & 64,7 & & \\
\hline & Alimentação & & & & & 100,0 & 55,7 & & \\
\hline
\end{tabular}

é a soma do deprimido cleaner e o flotado scavenger na etapa $n$.

No ensaio realizado sob a amostra, fizeram-se cinco flotações sucessivas com a metodologia do ensaio locked cycle, usou-se querosene como "coletor" com dosagens de $2.500 \mathrm{~g} / \mathrm{t}$, para a etapa rougher, e, $1.500 \mathrm{~g} / \mathrm{t}$, na etapa $s c a-$ venger. O óleo de pinho foi usado como espumante com dosagens de $300 \mathrm{~g} / \mathrm{t}$ para a etapa rougher, e de $180 \mathrm{~g} / \mathrm{t}$, para a eta- pa scavenger. A Figura 3 resume os resultados do ensaio. A Tabela 7 mostra a eficiência dessa separação em termos de recuperação de matéria carbonosa no flotado cleaner e rejeição de cinzas no deprimido final. 


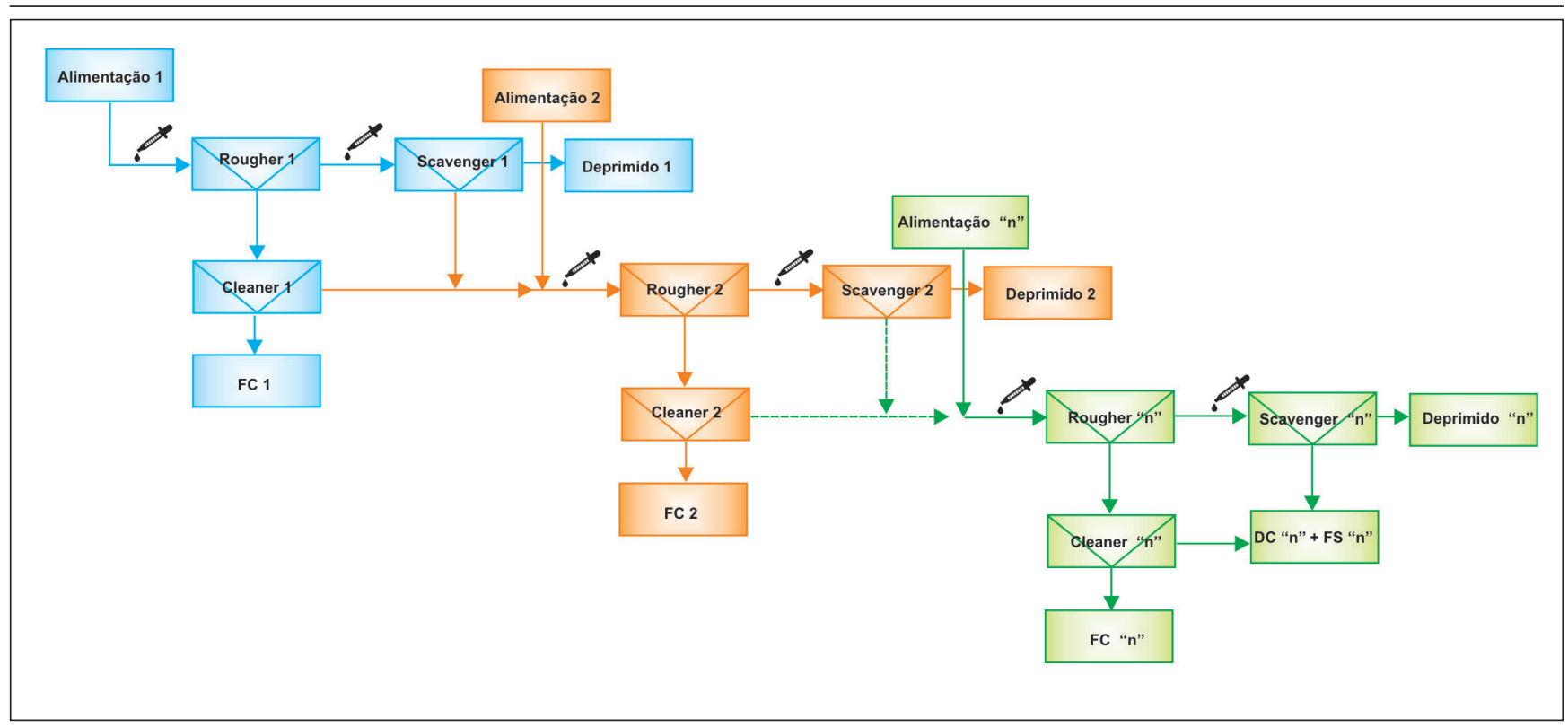

Figura 2 - Ensaio locked cycle para $n$ flotações sucessivas.

\section{Discussão dos resultados e conclusão}

O material objeto desse trabalho apresenta granulometria de tamanhos ultrafinos. A matéria carbonosa desse tamanho responde muito melhor frente à flotação, devido ao fato de o material estar liberado, de as partículas de carvão interagirem muito melhor com os reagentes e com as bolhas de ar. Trata-se de um material com alto conteúdo de cinzas, sendo que a metade do material é composta por matéria mineral, que, em sua maioria, são argilas e quartzo.

Dos "coletores" usados, o que melhor recuperação de matéria carbonosa apresentou foi o querosene. Ele foi usado com uma dosagem na etapa rougher de $2.500 \mathrm{~g} / \mathrm{t}$ e 1.500 na etapa scavenger. Essa dosagem alta deve-se, principalmente, ao tamanho das partículas. Em função de elas serem ultrafinas, a área superficial é muito grande. Dessa forma, precisa-se de altas quantidades de reagentes para cobrir a área das partículas envolvidas na flotação.

O óleo de pinho como espumante foi o que melhor comportamento e resultados mostrou. Obteve-se maior recuperação de massa e de matéria carbonosa,

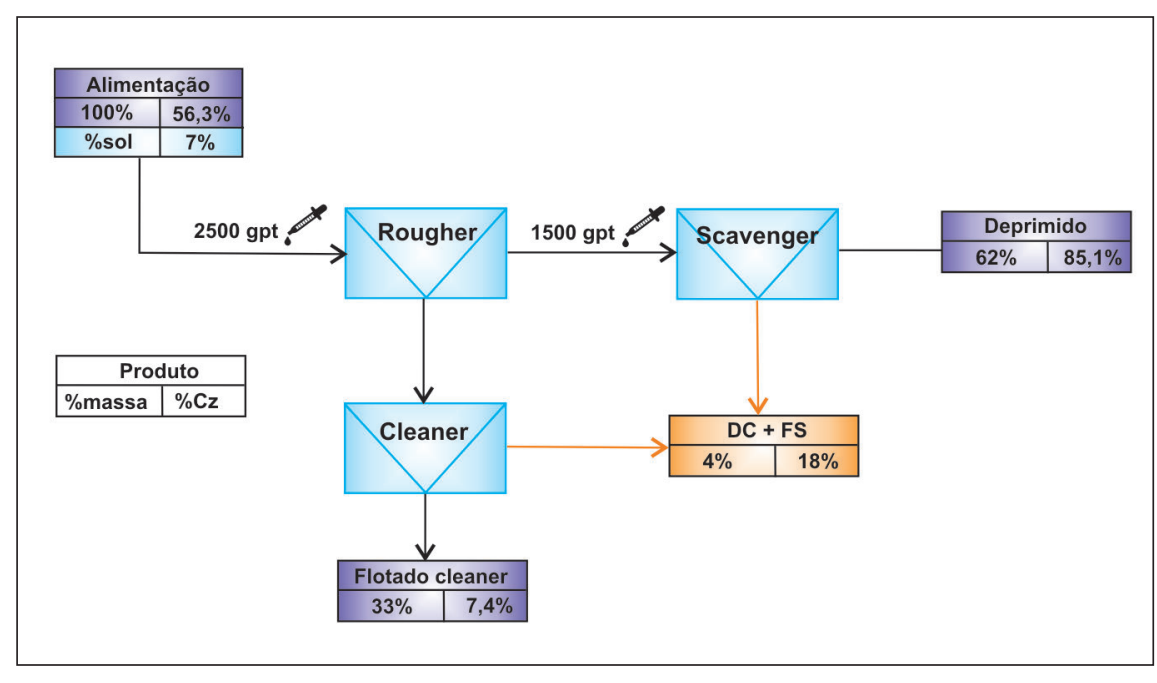

Figura 3 - Resumo do ensaio locked cycle.

Tabela 7 - Recuperações do ensaio locked cycle.

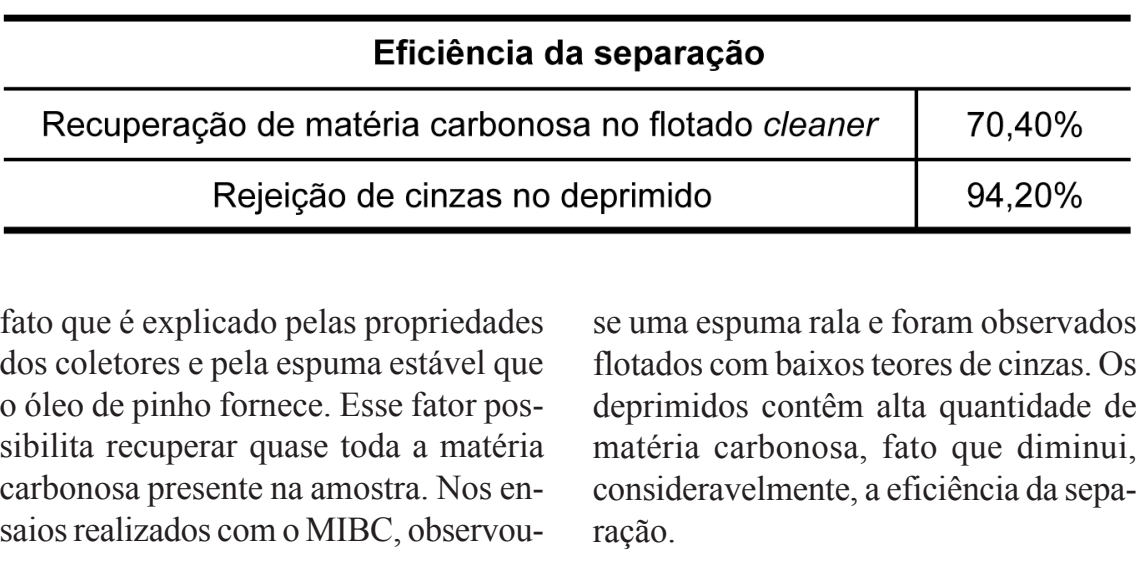


Os resultados de ensaio locked cycle mostram que é possível aumentar, consideravelmente, a recuperação mássica da separação, chegando-se a 33,3\%. Já a recuperação de matéria carbonosa, no flotado cleaner, atingiu $70,4 \%$ e a rejeição de cinzas aumentou, significativamente, chegando ao patamar de $94,2 \%$. Esses resultados indicam que, num circuito fechado, onde o material tenha várias oportunidades de limpeza, é possível recuperar uma grande quantidade do carvão contido na amostra e conseguir uma boa separação.

O material objeto desse trabalho é facilmente beneficiável por flotação, já que apresenta características que favorecem os processos físico-químicos de superfície, como são o grau de liberação, a granulometria e o rank do carvão (betuminoso), sendo que este último é o que garante o caráter hidrofóbico. $\mathrm{O}$ carvão flotado, que se obteve nessa pesquisa, possui um teor de cinzas de 7,4\% e análise imediata revelou que seu poder calorífico é $12.591 \mathrm{BTU} / \mathrm{Lb}$. Quando se passa pela base seca, seu poder calorífico chega a ser de $14.225 \mathrm{BTU} / \mathrm{Lb}$, o que representa um carvão de ótima qua- lidade no mercado energético. Além disto, esse carvão seria muito mais apreciado pela granulometria, já que ele é muito fino, portanto seu comportamento à combustão é favorecido.

A importante participação do carvão na matriz energética mundial obriga aos pesquisadores a desenvolver pesquisas voltadas para a eliminação dos impactos ambientais da mineração de carvão. A flotação, consagrada na recuperação de finos, poderá desempenhar um importante papel no processo de recuperação de partículas ultrafinas.

\section{Referências bibliográficas}

AMERICAN SOCIETY FOR TESTING AND MATERIALS. ASTM D3172: Standard practice for proximate analysis of coal and coke. West Conshohocken, 2007.

ASTM D5114: Standard test method for froth of coal in a mechanical cell. West Conshohocken, 2007.

CHAVES, A. P. Flotação de carvão de Santa Catarina (Região do Alto Metalúrgico). São Paulo: Escola Politécnica, Universidade de São Paulo, 1983. 142p. (Tese de Doutorado).

MENESES, C. T., ESCOBAR, A. T., CHAVES, A. P. Flotação de carvão no Brasil. In: CHAVES, A. P. Flotação. São Paulo: Signus, 2006. p. 444. (Série: Teoria e Práctica do Tratamento de Minérios).

MITCHELL, G. D., DAVIS, A., POLAT, H., CHANDER, S. The influence of photo-oxidation on the wettability of vitrinite from bituminous rank coal. In: CHIANG, S. H., 1996. Annual International Pittsburgh Coal Conference, 13. 1996, Pennsylvania. Anais... Pennsylvania, v. 2, p. 885-890.

POLAT, M., POLAT, H., CHANDER, S. Physical and chemical interactions in coal flotation. International Journal of Mineral Processing, v. 72, n. 1, p. 199-213, 2003.

ZIMMERMAN, R. E. Froth flotation. In: LEONARD, J. W. Coal Preparation. New York: The American Institute of Mining, Metallurgical and Petroleum Engineers, INC, 1979. c. 10. p. $75-104$. 